\title{
SEASONAL FLUCTUATION OF STABLE CARBON ISOTOPIC COMPOSITION IN JAPANESE CYPRESS TREE RINGS FROM THE LAST GLACIAL PERIOD- POSSIBILITY OF PALEOENVIRONMENT RECONSTRUCTION
}

\author{
Hiroshi Aoki Takahashi ${ }^{1} \bullet$ Hitoshi Yonenobu ${ }^{2} \cdot$ Toshio Nakamura $^{3} \bullet$ Hideki Wada $^{4}$
}

\begin{abstract}
Seasonal variations of $\delta^{13} \mathrm{C}$ were analyzed for two Japanese cypress trees (Chamaecyparis obtusa), one buried and one living. Both trees were different in age but sampled in areas geographically close to each other in central Japan. A buried cypress with 394 annual rings was excavated from Old Fuji mudflow, the last glacial strata of the dormant Mt. Fuji volcano. The accelerator mass spectrometry (AMS) radiocarbon date of this glacial sample was 18,600 $\pm 120 \mathrm{BP}$ (NUTA-4884). A living tree stem, which has 192 rings, was cut from the Izu Peninsula in 1986. In order to measure the seasonal $\delta^{13} \mathrm{C}$ fluctuation, the tree rings were divided equally into three earlywood and one or two latewood consecutive sections. The $\delta^{13} \mathrm{C}$ value within an annual ring generally increased from the first to the third or fourth sections then decreased in the last section. This pattern of the variation was similar in the glacial and modern samples. The $\delta^{13} \mathrm{C}$ value within an annual ring seems to be controlled by environmental factors (not plant physiological ones), since there was no isotopic shift in the seasonal $\delta^{13} \mathrm{C}$ variation at the earlywood-latewood boundary, which was controlled by plant physiology. The result suggests the potential to reconstruct the paleoenvironment within a year using the seasonal $\delta^{13} \mathrm{C}$ variation, though site-specific conditions such as soil characteristics would also affect to its fluctuation.
\end{abstract}

\section{INTRODUCTION}

Tree ring $\delta^{13} \mathrm{C}$ is often used as an environmental indicator. Many studies have suggested that the $\delta^{13} \mathrm{C}$ value of a tree is mainly controlled by climate, e.g. temperature, relative humidity and/or light levels (Farqhar et al. 1982) and the $\delta^{13} \mathrm{C}$ of atmospheric $\mathrm{CO}_{2}$ (Freyer and Belacy 1983). Some of these studies measured the seasonal $\delta^{13} \mathrm{C}$ fluctuations within tree rings (Wilson and Grinsted 1977; Leavitt and Long 1991; Kitagawa and Wada 1993; Ogle and McCormac 1994). Above all, Leavitt and Long (1991) used trees grown in arid or highland regions and revealed that the seasonal patterns were grouped by climate type, while Kitagawa and Wada (1993) reported that the patterns are mainly influenced by $\delta^{13} \mathrm{C}$ of atmospheric $\mathrm{CO}_{2}$. Tree ring $\delta^{13} \mathrm{C}$ shows the effect of environmental factors over hundreds of years with a resolution better than one year.

In this study, two trees were collected: one was living and the other was excavated from the mudflow of the last ice age. Such trees are often found in pyroclastic flow and ash-fall in volcanic regions in Japan. We measured $\delta^{13} \mathrm{C}$ for both trees to detect the seasonal fluctuation within a tree ring. The objectives of this study are to determine the age of the buried tree by accelerator mass spectrometry (AMS) radiocarbon dating and to estimate the potential to reconstruct paleoenvironment from seasonal $\delta^{13} \mathrm{C}$ fluctuation within a tree ring.

\section{SAMPLES AND METHOD}

Two stems of the same species, Japanese cypress (Chamaecyparis obtusa Endl.), were collected in central Japan (Figure 1). One was excavated from the Old Fuji mudflow strata of the Mt. Fuji volcano in 1969 (2.2 $\mathrm{m}$ in length and $65 \mathrm{~cm}$ in diameter), and designated as OFCO (Old Fuji mud flow, Chamaecyparis obtusa). A stratigraphical study (Tsuya 1968) suggested that this cypress had grown

\footnotetext{
${ }^{1}$ Department of Earth and Planetary Sciences, Graduate School of Science, Nagoya University, Nagoya 464-8602, Japan. Present affiliation: Research Center for Deep Geological Environments, Geological Survey of Japan, AISI, Tsakuba 3058567, Japan. E-mail: h.a.takahashi@aist.go.jp.

${ }^{2}$ College of Education, Naruto University of Education, Naruto 772-8502, Japan

${ }^{3}$ Center for Chronological Research, Nagoya University, Nagoya 464-8602, Japan

${ }^{4}$ Department of Biology and Geosciences, Shizuoka University, Shizuoka 422-8529, Japan
} 
during the last glacial period. The other sample was taken from a living tree at Mt Amagi in the Izu Peninsula in 1986 and designated as IACO (Izu Peninsula, Mt Amagi, Chamaecyparis obtusa). Transverse disks of OFCO and IACO were taken at about $30 \mathrm{~cm}$ and about $4 \mathrm{~m}$ height above the basal part of the stem, respectively. OFCO has 394 annual rings with a mean ring width of $0.70 \pm$ $0.24 \mathrm{~mm}$. The annual rings of OFCO are numbered from the innermost ring of the stem (ring Nos. 1-394). IACO has 192 annual rings (1794 AD to $1986 \mathrm{AD}$ ) with a mean ring width of $1.26 \pm$ $0.35 \mathrm{~mm}$. IACO had grown in an artificial forest and its growth had been affected by irregular human interference, i.e. thinning, pruning, and fertilizing. The annual mean ring width of IACO might be increased by these activities.

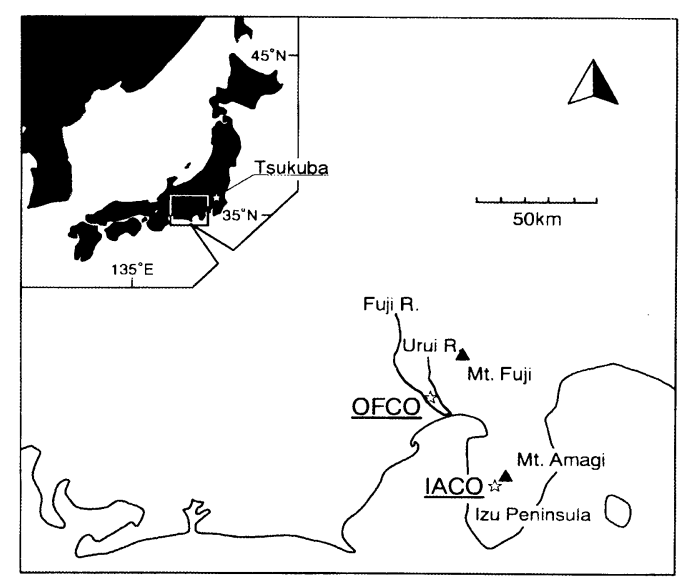

Figure 1 Sampling localities of Japanese cypress (Chamaecyparis obtusa Endl.)

The cellulose component ( $\alpha$-cellulose) was used to measure stable carbon isotopic ratios in this study. The thin-wood films of radial plane (about $150 \mu \mathrm{m}$ in thickness) sliced by a microtome were subdivided into five or four segments from one annual ring: three from earlywood and two or one from latewood using a razor blade under a zoom stereomicroscope, after benzene-alcohol treatment. Ten annual rings in OFCO (Nos. 156, 159, 160, 171-176, 179) and seven in IACO (1979-1985 AD) were analyzed for the seasonal variation of the $\delta^{13} \mathrm{C}$ values. The latewood width of IACO was too thin to be divided into two (Figure 2). The sliced films were neither ground nor milled because they are thin enough to be decomposed by chemical treatments with $\mathrm{NaClO}_{2}$ and $\mathrm{NaOH}$ for sample preparation.

Wood cellulose thus isolated was combusted in sealed Pyrex or Vycor tube with $\mathrm{CuO}$ at $550{ }^{\circ} \mathrm{C}$ for $10 \mathrm{hr}$ or at $850^{\circ} \mathrm{C}$ for $2 \mathrm{hr}$, respectively. It was confirmed that both combustion conditions gave identical $\delta^{13} \mathrm{C}$ values using a commercial reagent-grade cellulose powder. The sample gas was cryogenically purified to $\mathrm{CO}_{2}$ and its $\delta^{13} \mathrm{C}$ value was measured with isotope-ratio mass spectrometers (Finnigan MAT 250 at the Institute of Geoscience in Shizuoka University and Finnigan MAT 252 at the Center for Chronological Research in Nagoya University). The $\delta^{13} \mathrm{C}$ notation is conventionally presented with respect to the PDB standard (Craig 1957). Reference gas was calibrated to the average values of the NBS-19, NBS-20 and NBS-21 international standards at Nagoya University, and to NBS-20 at Shizuoka University. For the inter-laboratory reference check the $\delta^{13} \mathrm{C}$ values of the laboratory standard cellulose powder were measured to be $-25.26 \pm 0.06 \%$ o $(\mathrm{N}=23)$ at Shizuoka University and $-25.31 \pm 0.05 \% \circ(\mathrm{N}=8)$ at Nagoya University showing no significant difference with each other. 

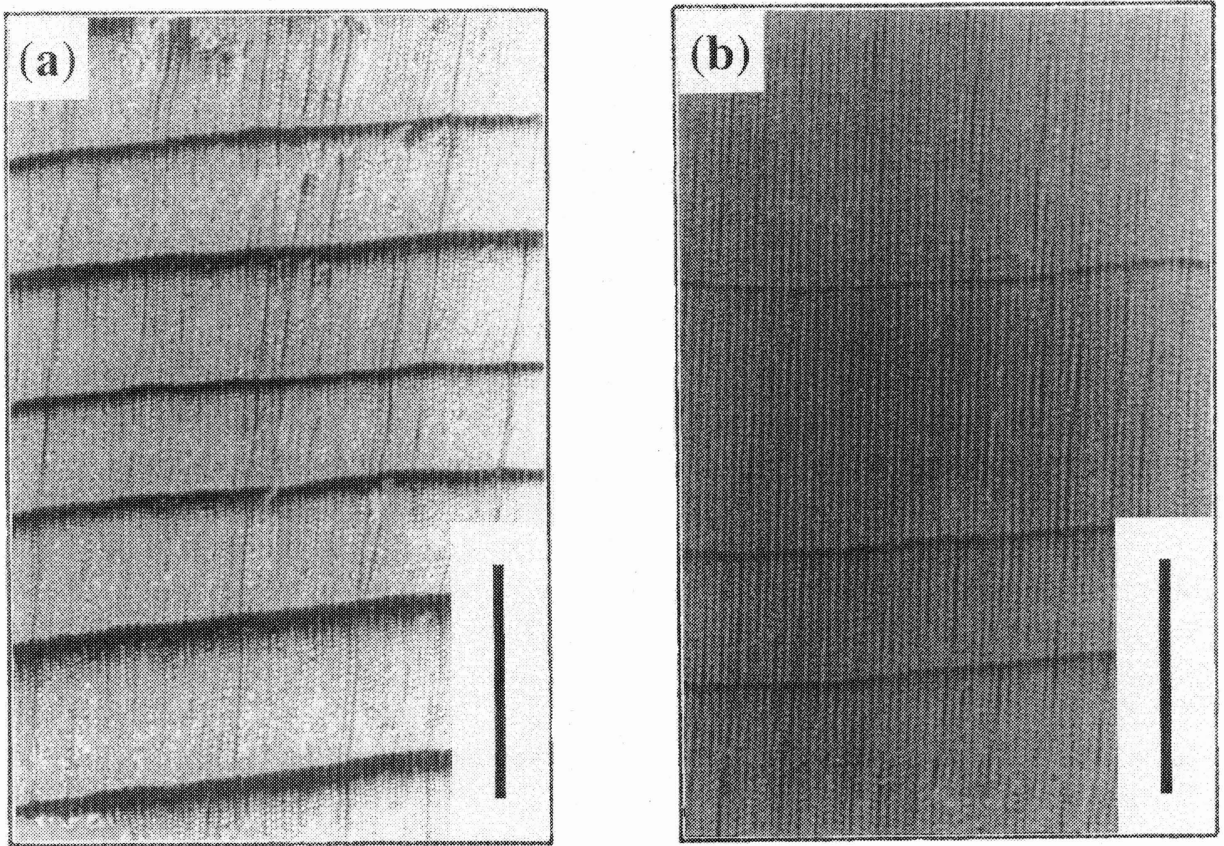

Figure 2 Micrographs of detailed structure in transverse plane (bar: 1mm) of OFCO (a) and IACO (b)

The ${ }^{14} \mathrm{C}$ sample was taken from the outermost ring (ring No. 394) of OFCO. The sample was treated in the A-A-A sequence and subsequently combusted at $850{ }^{\circ} \mathrm{C}$ for $2 \mathrm{hr}$. After cryogenic purification, the $\mathrm{CO}_{2}$ gas was reduced to graphite with hydrogen gas in a sealed tube (Kitagawa et al. 1993). The graphite targets prepared from sample and standard, NBS oxalic acid (Hox-II), were used for ${ }^{14} \mathrm{C}$ analysis with a Tandetron accelerator mass spectrometer at the Center for Chronological Research in Nagoya University (Nakamura et al. 1985). The isotopic fractionation was corrected using the sample $\delta^{13} \mathrm{C}$ value in evaluation of the ${ }^{14} \mathrm{C}$ age.

\section{RESULTS AND DISCUSSION}

\section{AMS ${ }^{14} \mathrm{C}$ Date of the Glacial Stem}

The newly measured ${ }^{14} \mathrm{C}$ date for OFCO is $18,600 \pm 120 \mathrm{BP}$ (NUTA-4884). This result is the first obtained by AMS ${ }^{14} \mathrm{C}$ dating, although it was measured by the beta counting method with a liquid scintillation counter to be 19,000 $\pm 500 \mathrm{BP}(\mathrm{Gak}-2319)$ in Tsuya (1971), 18,500 $\pm 300 \mathrm{BP}$ (JLS70011) in Yamada et al. (1972), 19,100 \pm 200 BP (SURBS-34) and 18,900 \pm 300 BP (SURBS-21) in Fukuhara and Wada (1997). All ${ }^{14} \mathrm{C}$ dates of OFCO are shown in Table 1 . The ${ }^{14} \mathrm{C}$ dates obtained here (NUTA-4884) and in Fukuhara and Wada (1997) were corrected for the carbon isotopic fractionation, while that reported by Yamada et al. (1972) was not. Tsuya (1971) did not give any correction. The $\delta^{13} \mathrm{C}$ values of $\mathrm{CO}_{2}$ gas in the present study and synthesized benzene in Fukuhara and Wada (1997) are -23.27\% (NUTA-4884), -23.88\% (SURBS-21) and -23.77\%。 (SURBS-34), respectively. The new AMS ${ }^{14} \mathrm{C}$ date is consistent with these conventional dates measured for outer part of OFCO, JLS-70011 and SURBS-21, within one standard deviation. 
Table 1 Radiocarbon dates of OFCO measured with different methods

\begin{tabular}{lllll}
\hline${ }^{14} \mathrm{C}$ dates (BP) & Ring nr & Method & Lab nr & Reference \\
\hline $18,600 \pm 120$ & 394 (outermost) & AMS & NUTA-4884 & Present study \\
$19,000 \pm 500$ & Not presented & Radiometric & Gak-2319 & Tsuya (1971) \\
$18,500 \pm 300$ & (Outer part) & Radiometric & JLS-70011 & Yamada et al. (1972) \\
$19,100 \pm 200$ & $1-30$ (inner part) & Radiometric & SURABS-34 & Fukuhara and Wada (1997) \\
$18,900 \pm 300$ & $364-394$ (outer part) & Radiometric & SURABS-21 & Fukuhara and Wada (1997) \\
\hline
\end{tabular}

\section{Comparison of Seasonal $\delta^{13} \mathrm{C}$ Fluctuation between Glacial and Modern Trees}

Figure 3 shows the $\delta^{13} \mathrm{C}$ fluctuations of cellulose within a tree ring of OFCO and IACO. In OFCO, the $\delta^{13} \mathrm{C}$ value of the first segment of earlywood is low and increases with growth, showing the highest value in the third segment of earlywood or the first segment of latewood. Other studies reported a similar seasonal pattern of tree ring $\delta^{13} \mathrm{C}$ (Wilson and Grinsted 1977; Leavitt and Long 1991; Kitagawa and Wada 1993). The $\delta^{13} \mathrm{C}$ fluctuations of IACO show a pattern similar those of OFCO. One different characteristic is that the latewood normally shows the lowest value in IACO. The $\delta^{13} \mathrm{C}$ values of the last segment of each ring are lower than previous ones. The mean amplitudes of the $\delta^{13} \mathrm{C}$ fluctuation within the annual rings of OFCO (10 years) and IACO (7 years) are $1.20 \pm 0.32 \%$ and $0.91 \pm 0.55 \%$, respectively. In order to compare the amplitude of the $\delta^{13} \mathrm{C}$ fluctuation for OFCO with that for IACO, the mean amplitude for OFCO was recomputed to have the same subdivision of the annual rings used for IACO ( 3 earlywood and 1 latewood), resulting in the value of $0.97 \pm 0.27$ $\%$. The amplitude of $\delta^{13} \mathrm{C}$ fluctuations for OFCO (glacial) is almost equal to that of IACO (modern) within one standard deviation.

The observed pattern and amplitude of seasonal $\delta^{13} \mathrm{C}$ fluctuations might be affected by latewood widths and the choice of subdivision counts. Latewood formation in trees is controlled by physiological factors. Because the latewood widths of OFCO are larger than those of IACO (Figure 2), we conclude that the period of latewood formation was longer in the last glacial period than at present. Field observations show that latewood of Japanese cypress is formed during dry conditions in the summer. Our results suggest that the growing environment of OFCO (glacial) might be drier than that of IACO (modern).

\section{Factors Controlling Seasonal $\delta^{13} \mathrm{C}$ Fluctuations}

The $\delta^{13} \mathrm{C}$ value of tree is controlled by climate and the $\delta^{13} \mathrm{C}$ values of atmospheric $\mathrm{CO}_{2}$ (Farquhar et al. 1982). In the $\mathrm{CO}_{2}$ fixation model of Farquhar et al. (1982), $\delta^{13} \mathrm{C}$ in plants is determined by the $\mathrm{CO}_{2}$ concentration ratio of intercellular space versus external atmosphere $\left(\mathrm{C}_{\mathrm{i}} / \mathrm{C}_{\mathrm{a}}\right)$ and the $\delta^{13} \mathrm{C}$ of atmospheric $\mathrm{CO}_{2}$. Kitagawa and Wada (1993) reported that the seasonal $\delta^{13} \mathrm{C}$ fluctuation of Japanese cedar (Cryptomeria japonica), which also grew at Mt. Amagi in Shizuoka Prefecture, central Japan (Figure 1), is mainly influenced by that of atmospheric $\mathrm{CO}_{2}$. They measured a mean fluctuation amplitude of $1.40 \pm 0.32 \%$ o for 21 annual rings from the 1860 s till the 1980 s, using five subdivisions ( 3 earlywood and 2 latewood). In the present study, the amplitude of IACO is $0.91 \%$. Inoue and Sugimura (1985) presented a monthly mean $\delta^{13} \mathrm{C}$ change of $0.61 \%$ in atmospheric $\mathrm{CO}_{2}$ in 1982 and 1983 at Tsukuba, Ibaraki prefecture, central Japan (Figure 1), during the growing period of Japanese cypress, from the middle of March to the end of October (Kuroda and Kiyono 1996). This change of atmospheric $\delta^{13} \mathrm{C}$ is smaller than that of IACO and Japanese cedar in Kitagawa and Wada (1993), although the $\delta^{13} \mathrm{C}$ amplitude within tree rings shows larger values according to the increase of subdivided counts from single tree rings, and is not smaller than $0.91 \% \circ$ or $1.40 \%$. Therefore, the 

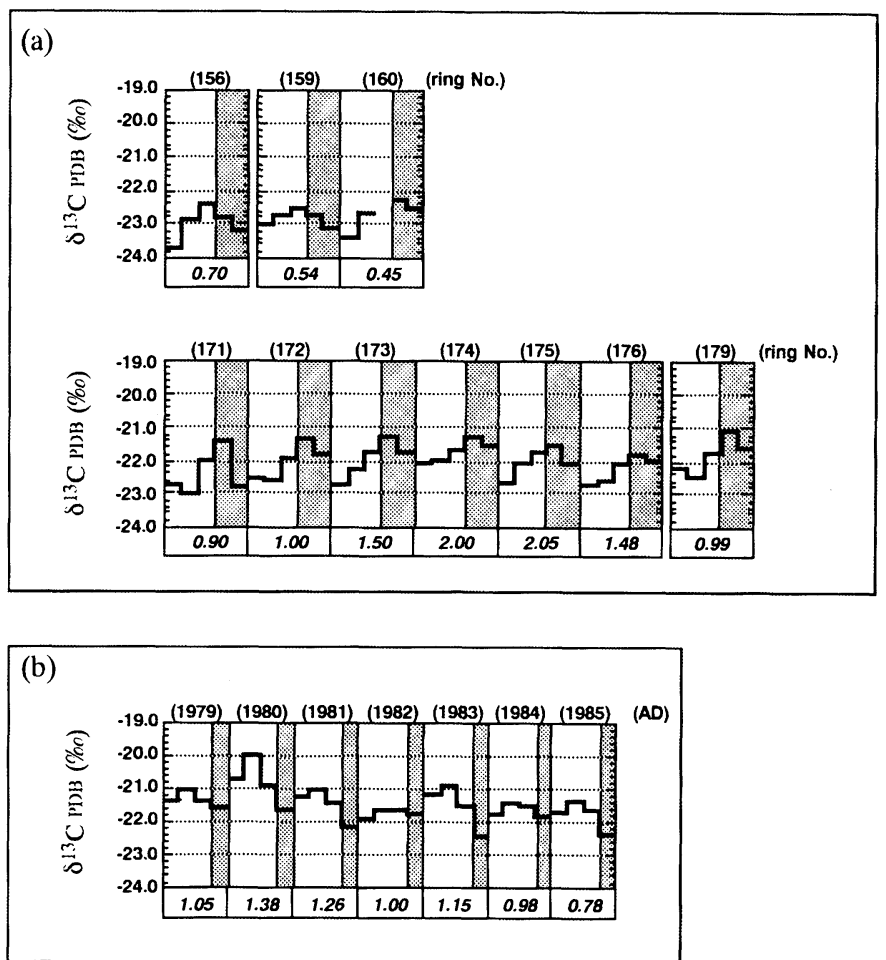

Figure 3 Seasonal $\delta^{13} \mathrm{C}$ fluctuations within annual rings of OFCO (a) and IACO (b). The shadowed parts show latewood. The numbers in parentheses indicate the ring numbers counted from innermost ring (OFCO) and growth year, AD (IACO). The italic numbers are the annual ring width $(\mathrm{mm})$

seasonal $\delta^{13} \mathrm{C}$ fluctuations of IACO can not be explained only by the changing of the $\delta^{13} \mathrm{C}$ values of atmospheric $\mathrm{CO}_{2}$ in the same interval.

The $\delta^{13} \mathrm{C}$ within an annual ring would be entirely controlled by environmental factors (not by plantphysiological ones). This is because there is no evident isotopic shift or abrupt change even in the early-latewood boundary of which morphological change is physiologically controlled, though the influence of environmental factors on the isotopic fractionation should be mostly identical for both. IACO shows the lowest value in latewood as also represented in Ogle and McCormac (1994). They reported the decrease of $\delta^{13} \mathrm{C}$ in the last of 24-35 contiguous segments of a single oak ring. While, the $\delta^{13} \mathrm{C}$ of the last segments of OFCO did not show the lowest values. This is simply due to the averaging of $\delta^{13} \mathrm{C}$ values for the last segments, since the formation period of the last (i.e. second) segment for OFCO might be longer than that for IACO (i.e. whole latewood). The latewood width is larger for OFCO than IACO (Figure 2). This might be the reason for the difference in seasonal $\delta^{13} \mathrm{C}$ pattern between OFCO and IACO. Thus, the seasonal $\delta^{13} \mathrm{C}$ fluctuations of OFCO and IACO might show the similar pattern except the last stage of growing season, and have possibility to indicate some environmental factors.

The results in the present study suggest that it is possible to reconstruct paleoenvironment using the seasonal $\delta^{13} \mathrm{C}$ fluctuations of past trees. Dominant factors influencing the $\delta^{13} \mathrm{C}$ fluctuations within tree rings are not yet clear and often controversial; only the simple expression in photosynthetic 
organs was successfully given by Farquhar et al. (1982). The in-situ measurement of tree ring $\delta^{13} \mathrm{C}$ should be important in order to fully understand isotopic fluctuations of tree rings and to use $\delta^{13} \mathrm{C}$ as proxy environmental data.

\section{CONCLUSION}

The seasonal $\delta^{13} \mathrm{C}$ fluctuations within annual rings for an ancient tree, which had been buried since the last glacial period (sample OFCO), and a living modern tree (sample IACO) of Japanese cypress are analyzed in this work. The ${ }^{14} \mathrm{C}$ age of $\mathrm{OFCO}$ is measured to be $18,600 \pm 120 \mathrm{BP}$ (NUTA-4884) using an AMS method. The $\delta^{13} \mathrm{C}$ values of OFCO are lower in the early stage of the growing season and higher in the later stage, showing similar characteristic patterns in the living tree (IACO).

\section{ACKNOWLEDGMENTS}

We are grateful to Professor Emeritus Yoji Kikata, Nagoya University, for his advice in sample preparation, and to the board of Education in Fujinomiya City for their kind permission to take glacial sample.

\section{REFERENCES}

Craig H. 1957. Isotopic standards for carbon and oxygen and correction factors for mass-spectrometric analysis of carbon dioxide. Geochimica et Cosmochimica Acta 12:133-49.

Farquhar GD, O'Leary MH, Berry JA. 1982. On the relationship between carbon isotope discrimination and intercelluler carbon dioxide concentration in leaves. Australian Journal of Plant Physiology 9:21-37.

Fukuhara T, Wada H. 1997. Radiocarbon age determination at Shizuoka University (I). Geoscience Reports of Shizuoka University 24:15-26. In Japanese with English abstract.

Freyer HD, Belacy N. $1983 .{ }^{13} \mathrm{C} /{ }^{12} \mathrm{C}$ records in Northern Hemispheric trees during the past 500 years-Anthropogenic impact and climatic superpositions. Journal of Geophysical Research 88:6844-52.

Inoue H, Sugimura Y. 1985. The carbon isotopic ratio of atmospheric carbon dioxide at Tsukuba, Japan. Journal of Atmospheric Chemistry 2:331-44.

Kitagawa H, Masuzawa T, Nakamura T, Matsumoto E. 1993. A batch preparation method for graphite targets with low background for AMS ${ }^{14} \mathrm{C}$ measurements. $R a$ diocarbon 35(2):295-300.

Kitagawa H, Wada H. 1993. Seasonal and secular $\delta^{13} \mathrm{C}$ variations in annual growth rings of a Japanese cedar tree from Mt. Amagi, Izu Peninsula, Central Japan. Geochemical Journal 27:391-6.

Kuroda K, Kiyono Y. 1996. Precise measurement of the radial growth of hinoki (Chamaecyparis obtusa) trunks with an artificial wound tissue analysis. Comparison with the dendrometer method. Nihon Ringakkaishi 78:183-9.

Leavitt SW, Long A. 1991. Seasonal stable-carbon isotope variability in tree rings: possible paleoenvironmental signals. Chemical Geology 87:59-70.

Nakamura T, Nakai N, Sakase T, Kimura M, Ohishi S, Taniguchi M, Yoshioka S. 1985. Direct detection of radiocarbon using accelerator techniques and its application to age measurements. Japan Journal of Applied Physics 24:1716-23.

Ogle N, McCormac FG. 1994. High-resolution $\delta^{13} \mathrm{C}$ measurements of oak show a previously unobserved spring depletion. Geophysical Research Letters 21: 2373-5.

Tsuya H. 1968. Geology of volcano Mt. Fuji. Geological Survey of Japan. 24 p. In Japanese.

Tsuya H. 1971. Topography and Geology of Volcano Mt. Fuji. Scientific report of Mt. Fuji, Fuji express Co. 149 p. In Japanese with English abstract.

Wilson AT, Grinsted MJ. 1977. ${ }^{12} \mathrm{C} /{ }^{13} \mathrm{C}$ in cellulose and lignin as palaeothermometers. Nature 265:133-5.

Yamada O, Wada H, Sameshima T. $1972 .{ }^{14} \mathrm{C}$ dating by liquid scintillation counting on synthesized methanol and its application on wooden remnants in ejecta of Fuji volcano. Journal of the Geological Society of Japan 78:235-9. In Japanese with English abstract. 